\title{
Variation of Femoral Component Size by Reference Points and Target Alignments in Total Knee Arthroplasty
}

\section{Shojiro Ishibashi}

Kyushu University

Hideki Mizu-uchi ( $\nabla$ himizu@ortho.med.kyushu-u.ac.jp )

Kyushu University

\section{Shinya Kawahara}

Kyushu University

\author{
Hidetoshi Tsushima \\ Kyushu University

\section{Yukio Akasaki \\ Kyushu University}

\section{Yasuharu Nakashima}

Kyushu University

\section{Research Article}

Keywords: total knee arthroplasty, femoral component size, computer simulation, reference guide, alignment

Posted Date: April 14th, 2021

DOI: https://doi.org/10.21203/rs.3.rs-404360/v1

License: (c) (1) This work is licensed under a Creative Commons Attribution 4.0 International License. Read Full License 


\section{Abstract}

Selecting appropriately sized components is important in total knee arthroplasty because they can affect postoperative knee function and pain. This study investigated size differences of 19 different femoral component placements from the standard position by three-dimensional virtual surgery using threedimensional bone models of 101 varus osteoarthritic knees. Distal femoral bone was cut perpendicular to the femoral mechanical axis (MA) in the coronal plane. Twenty different component placements consisting of five cutting directions (perpendicular to $\mathrm{MA}, 3^{\circ}$ and $5^{\circ}$ extension/flexion relative to $\mathrm{MA}$ in the sagittal plane), two rotational alignments (clinical and surgical epicondylar axes), and two rotational types of anterior reference guide (central and medial) were simulated. The mean anteroposterior dimension of the standard position was $55.5 \mathrm{~mm}$ which means that the difference compared to 19 different methods ranged from $-1.2 \pm 0.2 \mathrm{~mm}$ to $7.1 \pm 1.3 \mathrm{~mm}$. Multiple regression analysis revealed that flexion cutting direction, surgical epicondylar axis, and central were associated with smaller component size. In conclusion, the femoral component size can be affected easily by not only cutting direction but also the reference guide type and the target alignment. Our findings could provide surgeons with clinically useful information to fine-tune for unintended loose or tight joint gaps by adjusting the component size.

\section{Introduction}

Selecting appropriately sized components is important in total knee arthroplasty (TKA) because they can affect postoperative knee function and pain ${ }^{1}$. In the measured resection technique, optimal alignment can be achieved using a detailed preoperative planning system and several jigs. However, it is difficult to accurately determine proper component sizes because cutting surface conditions vary among intraoperative techniques despite accurate preoperative planning ${ }^{2}$. Larger components result in tighter flexion gaps, which can decrease range of motion, increase wear of inserts, and elevate patellofemoral joint pressure ${ }^{3-5}$. Smaller component sizes cause looser flexion gaps, which can cause knee instability and implant loosening ${ }^{1,6,7}$. The final decisions regarding component size were obtained by measuring the joint gap via a tensioning device using the gap balance technique, whereas the measured resection technique was obtained from a joint gap that consisted of the results of all intraoperative procedures. Surgeons should know effect of intraoperative procedures on the component size to avoid unintended loose or tight gaps.

The rotational alignment and position of the reference guide can affect component size. Generally, anterior and posterior reference guides are used to align to the target rotational alignment. The former can prevent notching at the anterior femoral condyle. However, the flexion gap may be altered by changes in posterior condyle thicknesses before and after bone cutting, making it difficult to select the appropriate component size ${ }^{6}$. Reference guides are also classified into three types according to the fulcrum rotation center: medial, central, and lateral. The rotation center affects posterior femoral condyle resection even if a posterior reference guide is used ${ }^{8}$. With the anterior reference guide, greater resection should cause a 
component size difference between the medial and central rotation types. No studies thus far have investigated how the rotation type of the anterior reference guide affects the femoral component size.

Several studies showed that femoral component size can be changed by preoperative planning 9,10 and intraoperative alignment ${ }^{11,12}$. However, most used a two-dimensional (2D) or three-dimensional (3D) templating system that evaluates component size on an inappropriately derived plane that is affected by limb position and selection of reference points ${ }^{13}$. Virtual surgery via computer simulation is useful for precisely evaluating the effects of different component placements during TKA, because it should reduce the effects of inaccurate alignment or inadequate observation by 2D or 3D templating system ${ }^{14}$. The purpose of this study was to evaluate the sizes of femoral components with 20 different component placements and investigate the size differences from the standard position in TKA using 3D virtual surgery with computer simulation. In addition, we sought to compare the size difference among cutting directions, rotational alignments, and rotational types of reference guide. The hypothesis is as follows. (1) Size can easily change from the standard position based on cutting directions, rotational alignments, and rotational types of the anterior reference guide. (2) Size significantly differs among cutting directions, rotational alignments, and reference guide rotation types.

\section{Results}

The ICC $(1,1)$ and ICC $(2,1)$ of this coordinate system were 0.97 and 0.96 , respectively, suggesting excellent agreement for both.

The mean femoral AP dimension and component size with 20 different component placements are shown in Table 1. The mean difference of AP dimension ranged from $54.3 \mathrm{~mm}$ to $62.5 \mathrm{~mm}$, which corresponded to 3.9-size difference in terms of the femoral component size (4.9 to 8.8). The mean AP dimension of the standard position was $55.5 \mathrm{~mm}$ which means that the difference compared to 19 different methods ranged from $-1.2 \mathrm{~mm}\left(5^{\circ} \mathrm{F}-\mathrm{MA}, \mathrm{SEA}\right.$, and CR) to $7.1 \mathrm{~mm}\left(5^{\circ} \mathrm{E}-\mathrm{MA}, \mathrm{CEA}\right.$, and MR). Significant larger sizes were selected compared to the standard position when cutting direction was $5^{\circ} \mathrm{E}-$ $\mathrm{MA}, 3^{\circ} \mathrm{E}-\mathrm{MA}$, and P-MA (Table 1). Despite of performing with $5^{\circ} \mathrm{F}-\mathrm{MA}$ and $3^{\circ} \mathrm{F}-\mathrm{MA}$ in cutting direction, significant larger sizes were selected compared to the standard position when the target rotational alignment was CEA and the reference guide was MR $(p<0.0001)$.

The mean femoral AP dimension and component size with five different cutting directions in sagittal alignment are shown in Table 2. The AP dimension and component size and increased with greater extension of the cutting direction. The component sizes with P-MA were significantly smaller than with $5^{\circ} \mathrm{E}-\mathrm{MA}$ and significantly larger than with $5^{\circ} \mathrm{F}-\mathrm{MA}$. The component sizes with P-MA differed significantly from those with $3^{\circ} \mathrm{E}-\mathrm{MA}$ and $3^{\circ} \mathrm{F}-\mathrm{MA}$ except for three methods $\left(3^{\circ} \mathrm{E}-\mathrm{MA}\right.$ using CEA/MR, $3^{\circ} \mathrm{E}-\mathrm{MA}$ using SEA/CR, and $3^{\circ} \mathrm{F}-\mathrm{MA}$ using SEA/MR). By contrast, no significant size differences were observed between $3^{\circ} \mathrm{E}-\mathrm{MA}$ and $5^{\circ} \mathrm{E}-\mathrm{MA}$ or between $3^{\circ} \mathrm{F}-\mathrm{MA}$ and $5^{\circ} \mathrm{F}-\mathrm{MA}$. 
The mean femoral AP dimension and component size with two different rotational alignments are shown in Table 3. The mean component sizes were not smaller in any knees using CEA than in knees using SEA. The AP dimension and mean component size with CEA as the target rotational alignment had a significantly larger size than that with SEA when a MR reference guide was used $(p<0.0001$; Table 3$)$. By contrast, about half of all knees (49.5 - 60.4\%) had a same component size with CEA compared with SEA when a CR reference guide was used (Table 3 ).

The mean femoral AP dimension and component size with two different reference guides are shown in Table 4. The mean AP dimension and component size with MR yielded a significantly larger size than with CR ( $p$ < 0.0001), and mean component sizes were not smaller in any knees using MR than in knees using CR when CEA was the target rotational alignment (Table 4). By contrast, fewer than half of knees (38.6 - $47.5 \%$ ) had a larger component size with MR than with CR, when SEA was the target rotational alignment (Table 4).

Multiple regression analysis showed that flexion cutting direction ( $\beta$ value: -0.43 ), SEA ( $\beta$ value: -0.19$)$, and CR ( $\beta$ value: -0.18 ) were associated with smaller component size respectively $(p<0.0001)$, and the association was strongest with cutting in flexion.

\section{Discussion}

The most important finding of this study was that intraoperative surgical techniques, including surgeons' selection of the reference guide type and the target alignment, readily affected the femoral component size. This suggests that it is difficult to achieve an accurate component size despite establishing a presumably accurate preoperative plan. The mean difference of AP dimension showed 8.2-mm ranged from $54.3 \mathrm{~mm}$ to $62.5 \mathrm{~mm}$, which corresponded to 3.9-size difference in terms of the femoral component size (4.9 to 8.8). The largest difference from the standard position was 7.1-mm in the femoral AP dimension, equivalent to 3.4 in the component size. Surgeons should be aware that inaccurate surgical techniques using conventional alignment guides and cutting blocks can not only cause difficulty in acquiring optimal alignment, but also readily change femoral component size. Few studies have examined the detailed effects of surgical techniques on component size ${ }^{9,13}$. Therefore, we accurately compared size differences resulting from 20 different component placements performed using virtual surgery and computer-assisted design software.

In all knees, cutting in extension resulted in a greater femoral AP dimension than cutting in flexion. Our accurate measurements showed a similar trend with a previous study using 3D templating software ${ }^{12}$. Furthermore, multiple regression analysis showed that cutting in flexion affected the femoral component size most negatively. The size changed significantly when the difference in cutting direction was more than $3^{\circ}$. In previous studies using conventional methods, only $45-65 \%$ of cases exhibited values within $3^{\circ}$ of the target angle in the sagittal plane ${ }^{20,21}$. To prevent unexpected component size changes, surgeons should be aware of several pitfalls related to cutting direction (for instance, inappropriate 
spacing between the distal femoral cutting guide and bone saw, and improper flexure of the bone saw edge).

Regardless of rotational alignment, no knees had a smaller component size when CEA was used as opposed to SEA. Both CEA and SEA were used for the target rotational alignment in this study because posterior condylar axis may not be suitable due to variety of bone deformities and cartilage thickness. Based on intraoperative measurements, Koninckx et al. reported that the AP dimension of the distal femur increased by $2.3 \mathrm{~mm}$ and $3.8 \mathrm{~mm}$ with $3^{\circ}$ and $5^{\circ}$ of external rotational alignment, respectively, relative to the posterior condylar axis ${ }^{11}$. Our study obtained similar results using the CEA and SEA as major target rotational alignments, because the CEA is usually externally aligned relative to the SEA. One reason for the larger component size when using the CEA can be explained based on the measurements shown in Fig. 3. The AP dimension was calculated using the following equations: AP dimension $(C E A)=r 1 \times \operatorname{sina}+$ $r 2 \times \sin \beta$, and AP dimension (SEA) $=r 1 \times \sin (a-\theta)+r 2 \times \sin (\beta-\theta)$. The distance between the knee center and the attachment of the anterior boom ( $r 1)$, and between the knee center and the rotation center of the reference guide ( $r 2$ ) on the $X Y$-plane, are the same when using the CEA and SEA. AP dimension (SEA) is smaller than AP dimension (CEA) due to the low value of the sine of $\theta$ (the angle between the CEA and SEA).

Regarding the effects of reference guide rotation types, almost no knees had a smaller component size when using MR rather than $\mathrm{CR}$ due to the longer AP dimension with MR. No studies have investigated how the rotation type of the anterior reference guide affects femoral component size. The reasons why the AP dimension is longer with MR than CR is simply because the rotation center is located more posteriorly with MR (Figs. 2A and 2B). When using the CEA, the component size is larger with MR than CR in most knees, but this is the case in only about half of all knees when using the SEA; this can be explained by calculations based on the measurements in Fig. 4. The difference in AP dimension when using MR versus $C R$ was calculated using the following equations: difference in AP dimension when using $M R$ versus $C R(C E A)=r 3 \times \sin \delta$, and difference in AP dimension when using MR versus $C R(S E A)=$ $r 3 \times \sin (\delta-\theta)(\delta$ : angle between the CEA and the posterior condylar axis). The distance between the rotation center on the $X Y$-plane when using MR versus $C R(r 3)$ is the same for both the CEA and SEA. The difference in AP dimension when using MR versus $C R(S E A)$ is smaller than the difference in AP dimension when using MR versus CR (CEA) due to the low value of the sine of $\theta$.

Understanding the effect of surgical techniques on the component size could provide surgeons performing the measured resection technique with clinically useful information to fine-tune the joint gap by adjusting the component size during surgery. Surgeons can downsize the component and increase the flexion gap by using CR instead of releasing the posterior cruciate ligament, as the latter may cause AP instability with cruciate-retaining implant types ${ }^{22}$. Surgeons can also upsize the component and decrease the flexion gap by using MR with posterior-stabilized implant types. In addition, it is possible to select either MR or CR when component oversize or undersize is predicted, both pre- and intraoperatively. 
There are several limitations to this study. First, no actual intraoperative measurements were performed. It may be useful to compare component sizes between MR and CR and/or between the CEA and SEA using computer-assisted surgery, however, the evaluations in this study should be reliable because accurate virtual surgical procedures were achieved using osteoarthritic knees before TKA. Second, no valgus osteoarthritic knees were included in this study; if they had been, our results may have been different. To minimize the potential influence of extraneous factors, we included only varus knees since these are most common at our institution. Despite these limitations, the results of this study suggest that understanding the effects of intraoperative surgical techniques on component size can help surgeons compensate for an unexpected joint gap, which can worsen knee function.

\section{Materials And Methods}

\section{Patients}

This study was approved by the medical ethics committee of Kyushu University Hospital review board (ID number of the approval: 2019-432) and performed in accordance with the Ethical Standards of the Helsinki Declaration. All methods were performed in accordance with the relevant guidelines and regulations. Informed consent was obtained from all patients before participation.

One hundred and one osteoarthritic knees with varus deformity were investigated in 88 patients before primary TKA. The study group consisted of 22 men ( 22 knees) and 66 women (79 knees). The mean patient age was $76.4 \pm 7.2$ (58 to 91 ) years. The mean patient height and weight were $152.3 \pm 8.2$ (135.9 to 178.5$) \mathrm{cm}$ and $62.1 \pm 12.8$ (39.9 to 94.2$) \mathrm{kg}$, respectively. The mean preoperative maximum flexion angle was $-5.2 \pm 7.5^{\circ}\left(-25^{\circ}\right.$ to $\left.0^{\circ}\right)$. The mean flexion deformity was $121.7 \pm 33.2^{\circ}\left(60^{\circ}\right.$ to $\left.140^{\circ}\right)$. Individuals with rheumatoid arthritis, a history of knee injuries or infections, or severe bone defects in the distal femur were excluded. The preoperative alignments and progression of osteoarthritic knees (determined using the Kellgren-Lawrence (K-L) osteoarthritis knee scale) ${ }^{15}$ were measured on full-length, weight-bearing anteroposterior (AP) radiographs using a digital measurement software 2D template (Japan Medical Materials Corp., Osaka, Japan). The mean preoperative femorotibial angle was $185.4 \pm 5.5^{\circ}$ and hip-kneeankle angle was $193.2 \pm 8.0^{\circ}$. Ninety-one knees were classified as grade 4 on the K-L scale, and 10 knees as grade 3 .

\section{Three-dimensional Bone Model and the Coordinate System}

A computed tomography (CT) scan of the lower extremity that was scheduled to undergo TKA was obtained from each patient within 3 months preoperatively (Aquilion 64-slice CT Scanner; Toshiba, Tochigi, Japan). CT slices were $2 \mathrm{~mm}$ thick. A 3D femoral bone model was reconstructed from preoperative CT data using MIMICS (Materialise, Leuven, Belgium). The bony geometry was imported into a computer-assisted design software program (Rhinoceros; Robert McNeel and Associates, Seattle, WA, USA) in stereolithography format. The coordinate system consisted of the femoral mechanical axis (MA) and the functional transepicondylar axis (TEA), which was projected onto the plane perpendicular to 
femoral MA (Fig. 1A) ${ }^{16}$. The center of the hip was determined by fitting a sphere to the femoral head. The center of the knee joint was identified as the midpoint of the TEA, which consisted of the surgical epicondylar axis (SEA) and clinical epicondylar axis (CEA). The femoral MA was defined as the line connecting the center of the knee and the center of the hip. The SEA was defined as the line connecting the most prominent point of the lateral epicondyle with the deepest point of the sulcus on the medial epicondyle. The CEA was defined as the line connecting the most prominent point of the lateral epicondyle with the most prominent point anterior to the medial sulcus of the medial epicondyle. The Zaxis of the knee (proximal-distal) was defined as the extension of the femoral MA. The plane normal to the Z-axis at the center of the knee was defined as the XY-plane. The Y-axis (medial-lateral) was defined as the extension of the functional TEA. The X-axis (anterior-posterior) was defined as the line normal to the coronal plane (YZ-plane) at the center of the knee (Fig. 1A).

\section{Virtual Surgery}

Bone cutting and implantation were performed on the femoral bone model using the established 3D coordinates. Cutting of the distal femur was performed to be perpendicular to the femoral MA (Z-axis) at the level of intercondylar notch in the coronal plane (Fig. 1B). In the sagittal plane, five different cutting directions were simulated: perpendicular to the femoral MA (P-MA), $3^{\circ}$ and $5^{\circ}$ extension relative to the femoral MA ( $3^{\circ} \mathrm{E}-\mathrm{MA}$ and $\left.5^{\circ} \mathrm{E}-\mathrm{MA}\right)$, and $3^{\circ}$ and $5^{\circ}$ flexion relative to the femoral MA ( $3^{\circ} \mathrm{F}-\mathrm{MA}$ and $5^{\circ} \mathrm{F}-\mathrm{MA}$, respectively) (Fig. 1 C).

Medial rotation (MR) and central rotation (CR) types of reference guides were used to determine the rotational alignment (Figs. 2A and 2B) ${ }^{6}$. The target rotational alignments were the CEA and SEA. The reference guide was positioned on the cutting surface and the foot of the guide was attached to the posterior condyles. An anterior reference guide was used to measure the femoral AP dimension. The anterior boom was positioned at the lateral sulcus point at the intersection of the anterior cortex and the top of the anterior condyle (Figs. 2A and 2B). The femoral AP dimension was defined as the distance between the attachment of the anterior boom and the rotation center of the reference guide in the XYplane ${ }^{17}$. A computer-assisted design model of the Persona Knee System (Zimmer-Biomet, Warsaw, IN, USA) was virtually implanted after completing the distal femoral bone cut using the preplanned size. Standard Persona sizes from 3 to 11 were selected to avoid exceeding the femoral AP dimension. The AP dimension of computer-assisted design model was $49.3 \mathrm{~mm}$ at size 3 and $66.2 \mathrm{~mm}$ at size 11, and each one-size increase in the Persona model resulted in a mean AP dimension change of $2.1 \mathrm{~mm}$.

The mean AP dimension and femoral component size were evaluated by virtual surgery using 20 different component placements, based on combinations of the following: five cutting directions (P-MA, $3^{\circ} \mathrm{E}-\mathrm{MA}, 5^{\circ} \mathrm{E}-\mathrm{MA}, 3^{\circ} \mathrm{F}-\mathrm{MA}$, and $5^{\circ} \mathrm{F}-\mathrm{MA}$ ) in the sagittal plane, two rotational alignments (CEA and SEA), and two reference guide rotation types (MR and CR). The sizes of 19 different component placements were compared with the standard position which was defined as [ $3^{\circ} \mathrm{F}-\mathrm{MA}, \mathrm{SEA}$, and $\left.\mathrm{CR}\right]^{18}$.

\section{Statistical analysis}


Data are presented as means and standard deviations. Data analysis was performed using JMP Pro software version 12.0 (SAS Institute, Cary, NC, USA). To investigate the reliability and reproducibility of this coordinate system for measuring AP dimension, intraobserver and interobserver reliabilities were

assessed using intra- and interclass correlation coefficients, i.e., ICC $(1,1)$ and ICC $(2,1)$, respectively ${ }^{19}$. All measurements were obtained by two orthopedic surgeons $(\mathrm{SI}, \mathrm{HM})$ at an interval of more than 1 week. Data were blinded and included no patient information. Student's t-test was used to compare differences between the CEA and SEA and between MR and CR. Different cutting directions in sagittal alignment and deviations from the standard position were compared between groups using ANOVA. Post hoc analysis was conducted using the Steel-Dwass test. Multiple regression analysis was performed to determine which factors had the greatest effect on component size, using the following factors: five cutting directions, two rotational alignments, and two rotational types of the reference guide (effect size: $\beta$ coefficient). Statistical significance was set at a $p$ value $<0.05$.

\section{Declarations}

\section{Author Contributions Statement:}

All authors have read and approved the final submitted manuscript. Contributions of the authors are as follows: S. I(1, 2, 3, 4, 5, 6), H. M $(1,2,3,4,5,6)$, S. K $(1,2,6)$, H. T $(1,2,6)$, Y. A $(1,2,6)$, Y. N $(1,2,3,4,5,6)$.

[1] The conception and design, [2] Acquisition or analysis of data, [3] Interpretation of data, [4] Drafting of the article, [5] Critical revision of the article for important intellectual content, [6] Final approval of the article

\section{Compliance with ethical standards}

\section{Competing interests}

The authors declare no competing interests.

\section{Ethical approval}

The study was approved by the institutional review board.

\section{Informed consent}

Informed consent was obtained from all individual participants included in this study.

\section{References}

1. Bonnin, M. P., Schmidt, A., Basiglini, L., Bossard, N., Dantony, E. Mediolateral oversizing influences pain, function, and flexion after TKA. Knee Surg Sports Traumatol Arthrosc, 21:2314-2324. doi: 10.1007/s00167-013-2443-x (2013). 
2. Maderbacher, G., et al. Appropriate sagittal femoral component alignment cannot be ensured by intramedullary alignment rods. Knee Surg Sports Traumatol Arthrosc, 24:2453-2460. doi: 10.1007/s00167-015-3541-8 (2016).

3. Kawahara $S$, et al. Upsizing the femoral component increases patellofemoral contact force in total knee replacement. J Bone Joint Surg [Br], 94-B:56-61. doi: 10.1302/0301-620X.94B1.27514 (2012).

4. Bong, M. R., Di Cesare, P. E. Stiffness After Total Knee Arthroplasty. J Am Acad Orthop Surg, 12:164171. doi: 10.5435/00124635-200405000-00004 (2004).

5. Michael, R. S., Richard, D. S. Posterior Polyethylene Wear in Posterior Cruciate Ligament-retaining total knee arthroplasty. A case study. J Arthroplasty, 8:439-446. doi: 10.1016/s0883-5403(06)800458 (1993).

6. Charette, R. S., Sheth, N. P., Boettner, F., Scuderi, G. R., Melnic, C. M. Femoral Component Sizing During Total Knee Arthroplasty: Anterior Versus Posterior Referencing. JBJS Rev, 6:e4. doi: 10.2106/JBJS.RVW.17.00051 (2018).

7. De, Valk, E. J., Noorduyn, J. C., Mutsaerts, E. L. How to assess femoral and tibial component rotation after total knee arthroplasty with computed tomography: a systematic review. Knee Surg Sports Traumatol Arthrosc, 24:3517-3528. doi: 10.1007/s00167-016-4325-5 (2016).

8. Minoda, Y., et al. Posterior reference guides do not always maintain the size of posterior femoral condyles in TKA. Knee Surg Sports Traumatol Arthrosc, 24:2489-2495. doi: 10.1007/s00167-0153706-5 (2016).

9. Kniesel, B., Konstantinidis, L., Hirschmuller, A., Sudkamp, N., Helwig, P. Digital templating in total knee and hip replacement: an analysis of planning accuracy. Int Orthop, 38:733-739. doi: 10.1007/s00264013-2157-1 (2014).

10. Ooka, N. H. M., Campos, A. L. S., da Fonseca, V. M., Rodrigues, L. E. O., Filho, E. B., Franko, J. S., E Albuquerque, R. S. P., Gamerio, V.S. Pre-operative templating for knee arthroplasty shows low accuracy with standard X-rays. Int Orthop, 42:1275-1282. doi: 10.1007/s00264-018-3764-7 (2018)

11. Koninckx, A., Deltour, A., Thienpont, E. Femoral sizing in total knee arthroplasty is rotation dependant. Knee Surg Sports Traumatol Arthrosc, 22:2941-2946. doi: 10.1007/s00167-013-2707-5 (2014).

12. Nakahara, H., Matsuda, S., Okazaki, K., Tashiro, Y., Iwamoto, Y. Sagittal cutting error changes femoral anteroposterior sizing in total knee arthroplasty. Clin Orthop Relat Res, 470:3560-3565. doi: 10.1007/s11999-012-2397-1 (2012).

13. Miura, M., Hagiwara, S., Nakamura, J., Wako, Y., Kawarai, Y., Ohtori, S. Interobserver and Intraobserver Reliability of Computed Tomography-Based Three-Dimensional Preoperative Planning for Primary Total Knee Arthroplasty. J Arthroplasty, 33:1572-1578. doi: 10.1016/j.arth.2017.12.035 (2018).

14. Ma, Y. et al. Bony landmarks with tibial cutting surface are useful to avoid rotational mismatch in total knee arthroplasty. Knee Surg Sports Traumatol Arthrosc, 27:1570-1579. doi: 10.1007/s00167018-5052-x (2019).

15. Kerrgren, J. H., Lawrence, J. S. Radiological assessment of osteo-arthrosis. Ann Rheum Dis. 16:494502. doi: 10.1136/ard.16.4.494 (1957). 
16. Mizu-uchi, H., Colwell, Jr. C. W., Matsuda, S., Flores-Hernandez, C., Iwamoto, Y., D'Lima, D. D. Effect of total knee arthroplasty implant position on flexion angle before implant-bone impingement. J Arthroplasty, 26:721-727. doi: 10.1016/j.arth.2010.08.002 (2011).

17. Dai, Y., Scuderi, G. R., Penninger, C., Bischoff, J. E., Rosenberg, A. Increased shape and size offerings of femoral components improve fit during total knee arthroplasty. Knee Surg Sports Traumatol Arthrosc, 22:2931-2940. doi: 10.1007/s00167-014-3163-6 (2014).

18. Koenen, P., Ates, D. M., Pfeiffer, T. R., Bouillon, B., Bathis, H. Femoral flexion position is a highly variable factor in total knee arthroplasty: an analysis of 593 conventionally aligned total knee replacements. Knee Surg Sports Traumatol Arthrosc, 28:1014-1022. doi: 10.1007/s00167-019-055486 (2020).

19. Walter, S. D., Eliasziw, M., Donner, A. Sample size and optimal designs for reliability studies. Stat Med., 17:101-110. doi: 10.1002/(sici)1097-0258(19980115)17:1<101::aid-sim727> 3.0.co;2-e (1998)

20. Mizu-uchi, H., Matsuda, S., Miura, H., Okazaki, K., Akasaki, Y., Iwamoto, Y. The evaluation of postoperative alignment in total knee replacement using a CT-based navigation system. J Bone Joint Surg [Br], 90-B:1025-1031. doi: 10.1302/0301-620X.90B8.20265 (2008).

21. Pfitzner, T., Abdel, M. P., von Roth, P., Perka, C., Hommel, H. Small improvements in mechanical axis alignment achieved with MRI versus CT-based patient-specific instruments in TKA: a randomized clinical trial. Clin Orthop Relat Res, 472:2913-2922. doi: 10.1007/s11999-014-3784-6 (2014).

22. Matsumoto T, et al. Soft tissue balance measurement in minimal incision surgery compared to conventional total knee arthroplasty. Knee Surg Sports Traumatol Arthrosc, 19:880-886. doi: 10.1007/s00167-010-1224-z (2011).

\section{Tables}

Table 1. Mean anteroposterior dimension and component size with twenty different component placements 


\begin{tabular}{|c|c|c|c|c|c|}
\hline $\begin{array}{l}\text { Cutting } \\
\text { directions }\end{array}$ & $\begin{array}{l}\text { Rotational } \\
\text { alignment }\end{array}$ & $\begin{array}{l}\text { Reference } \\
\text { guide }\end{array}$ & $\begin{array}{l}\text { AP } \\
\text { dimension } \\
(\mathrm{mm}) \\
\text { (component } \\
\text { size) }\end{array}$ & $\begin{array}{l}\text { AP dimension difference (mm) } \\
\text { compared with standard position } \\
\text { (Size difference) }\end{array}$ & p-value \\
\hline $3^{\circ} \mathrm{F}-\mathrm{MA}$ & SEA & CR & $\begin{array}{l}55.5 \pm 3.5 \\
(5.4 \pm 1.7)\end{array}$ & & \\
\hline $5^{\circ} \mathrm{E}-\mathrm{MA}$ & CEA & MR & $\begin{array}{l}62.5 \pm 4.0 \\
(8.8 \pm 1.7)\end{array}$ & $7.1 \pm 1.3(3.4 \pm 0.7)$ & $<0.0001$ \\
\hline $5^{\circ} \mathrm{E}-\mathrm{MA}$ & CEA & CR & $\begin{array}{l}60.3 \pm 3.7 \\
(7.7 \pm 1.7)\end{array}$ & $4.9 \pm 0.8(2.4 \pm 0.6)$ & $<0.0001$ \\
\hline $5^{\circ} \mathrm{E}-\mathrm{MA}$ & SEA & MR & $\begin{array}{l}60.3 \pm 4.0 \\
(7.7 \pm 1.8)\end{array}$ & $4.9 \pm 1.3(2.4 \pm 0.8)$ & $<0.0001$ \\
\hline $5^{\circ} \mathrm{E}-\mathrm{MA}$ & SEA & CR & $\begin{array}{l}59.4 \pm 3.7 \\
(7.4 \pm 1.7)\end{array}$ & $3.9 \pm 0.8(2.0 \pm 0.6)$ & $<0.0001$ \\
\hline $3^{\circ} \mathrm{E}-\mathrm{MA}$ & CEA & MR & $\begin{array}{l}61.7 \pm 3.9 \\
(8.3 \pm 1.7)\end{array}$ & $6.3 \pm 1.1(3.0 \pm 0.6)$ & $<0.0001$ \\
\hline $3^{\circ} \mathrm{E}-\mathrm{MA}$ & CEA & CR & $\begin{array}{l}59.4 \pm 3.6 \\
(7.3 \pm 1.6)\end{array}$ & $4.0 \pm 0.6(1.9 \pm 0.5)$ & $<0.0001$ \\
\hline $3^{\circ} \mathrm{E}-\mathrm{MA}$ & SEA & MR & $\begin{array}{l}59.4 \pm 3.9 \\
(7.3 \pm 1.8)\end{array}$ & $4.0 \pm 1.1(1.9 \pm 0.6)$ & $<0.0001$ \\
\hline $3^{\circ} \mathrm{E}-\mathrm{MA}$ & SEA & $\mathrm{CR}$ & $\begin{array}{l}58.5 \pm 3.6 \\
(6.9 \pm 1.7)\end{array}$ & $3.1 \pm 0.6(1.5 \pm 0.5)$ & $<0.0001$ \\
\hline P-MA & CEA & MR & $\begin{array}{l}60.3 \pm 3.8 \\
(7.7 \pm 1.7)\end{array}$ & $4.8 \pm 1.0(2.3 \pm 0.7)$ & $<0.0001$ \\
\hline P-MA & CEA & CR & $\begin{array}{l}58.0 \pm 3.5 \\
(6.7 \pm 1.7)\end{array}$ & $2.5 \pm 0.4(1.3 \pm 0.5)$ & $<0.0001$ \\
\hline P-MA & SEA & MR & $\begin{array}{l}58.0 \pm 3.8 \\
(6.6 \pm 1.9)\end{array}$ & $2.5 \pm 1.0(1.2 \pm 0.6)$ & $<0.0001$ \\
\hline P-MA & SEA & CR & $\begin{array}{l}57.1 \pm 3.6 \\
(6.2 \pm 1.7)\end{array}$ & $1.6 \pm 0.3(0.8 \pm 0.4)$ & 0.0013 \\
\hline $3^{\circ} \mathrm{F}-\mathrm{MA}$ & CEA & MR & $\begin{array}{l}58.6 \pm 3.8 \\
(6.9 \pm 1.7)\end{array}$ & $3.2 \pm 1.0(1.6 \pm 0.6)$ & $<0.0001$ \\
\hline $3^{\circ} \mathrm{F}-\mathrm{MA}$ & CEA & $\mathrm{CR}$ & $\begin{array}{l}56.4 \pm 3.5 \\
(5.9 \pm 1.7)\end{array}$ & $0.9 \pm 0.4(0.5 \pm 0.5)$ & 0.0562 \\
\hline $3^{\circ} \mathrm{F}-\mathrm{MA}$ & SEA & MR & $\begin{array}{l}56.4 \pm 3.7 \\
(5.9 \pm 1.8)\end{array}$ & $0.9 \pm 0.9(0.5 \pm 0.6)$ & 0.0682 \\
\hline $5^{\circ} \mathrm{F}-\mathrm{MA}$ & CEA & MR & $\begin{array}{l}57.5 \pm 3.7 \\
(6.5 \pm 1.8)\end{array}$ & $2.1 \pm 1.0(1.2 \pm 0.6)$ & $<0.0001$ \\
\hline
\end{tabular}




\begin{tabular}{|cccccc|}
$5^{\circ} \mathrm{F}-\mathrm{MA}$ & $\mathrm{CEA}$ & $\mathrm{CR}$ & $\begin{array}{r}55.2 \pm 3.4 \\
(5.4 \pm 1.6)\end{array}$ & $-0.2 \pm 0.4(0.0 \pm 0.4)$ & 0.6594 \\
\hline $5^{\circ} \mathrm{F}-\mathrm{MA}$ & $\mathrm{SEA}$ & $\mathrm{MR}$ & $\begin{array}{r}55.2 \pm 3.7 \\
(5.4 \pm 1.8)\end{array}$ & $-0.2 \pm 0.9(0.0 \pm 0.6)$ & 0.668 \\
\hline $5^{\circ} \mathrm{F}-\mathrm{MA}$ & SEA & CR & $\begin{array}{r}54.3 \pm 3.4 \\
(4.9 \pm 1.7)\end{array}$ & $-1.2 \pm 0.2(-0.5 \pm 0.5)$ & 0.0182 \\
\hline
\end{tabular}

The values are given as the mean with standard deviation.

Standard position was defined as ( $3^{\circ} \mathrm{F}-\mathrm{MA}$, SEA, and CR).

AP: anteroposterior, MA: Mechanical axis, CEA: Clinical epicondylar axis, SEA: Surgical epicondylar axis, MR: Medial rotation type of reference guide, CR: Central rotation type of reference guide, P-MA:

Perpendicular to MA, $3^{\circ} \mathrm{E}-\mathrm{MA}: 3^{\circ}$ extension to MA, $5^{\circ} \mathrm{E}-\mathrm{MA}: 5^{\circ}$ extension to MA, $3^{\circ} \mathrm{F}-\mathrm{MA}: 3^{\circ}$ flexion to MA, $5^{\circ} \mathrm{F}-\mathrm{MA}: 5^{\circ}$ flexion to $\mathrm{MA}$

Table 2. Mean anteroposterior dimension and component size with five different cutting directions in sagittal alignment 


\begin{tabular}{|c|c|c|c|c|c|c|c|c|}
\hline \multirow[b]{2}{*}{$\begin{array}{l}\text { CEA } \\
\text { MR }\end{array}$} & \multirow{2}{*}{$\begin{array}{l}5^{\circ} \text { E-MA } \\
62.5 \pm \\
4.0 \\
(8.8 \pm \\
1.7)\end{array}$} & \multirow{2}{*}{$\begin{array}{l}3^{\circ} \text { E-MA } \\
61.7 \pm \\
3.9 \\
(8.3 \pm \\
1.7)\end{array}$} & \multirow{2}{*}{$\begin{array}{l}\text { P-MA } \\
60.3 \pm \\
3.8 \\
(7.7 \pm \\
1.8)\end{array}$} & \multirow{2}{*}{$\begin{array}{l}3^{\circ} \mathrm{F}-\mathrm{MA} \\
58.6 \pm \\
3.8 \\
(6.9 \pm \\
1.7)\end{array}$} & \multirow{2}{*}{$\begin{array}{l}5^{\circ} \text { F-MA } \\
57.5 \pm \\
3.7 \\
(6.5 \pm \\
1.8)\end{array}$} & \multirow{2}{*}{$\begin{array}{l}\text { ANOVA } \\
<.0001\end{array}$} & \multicolumn{2}{|c|}{ Steel-Dwass test } \\
\hline & & & & & & & $\begin{array}{l}a: p= \\
0.0003 \\
b: p< \\
0.0001 \\
c: p< \\
0.0001 \\
e: p< \\
0.0001\end{array}$ & $\begin{array}{l}f: p< \\
0.0001 \\
g: p= \\
0.0332 \\
h: p= \\
0.0002\end{array}$ \\
\hline $\begin{array}{l}\text { CEA } \\
\text { CR }\end{array}$ & $\begin{array}{l}60.3 \pm \\
3.7 \\
(7.7 \pm \\
1.7)\end{array}$ & $\begin{array}{l}59.4 \pm \\
3.6 \\
(7.3 \pm \\
1.6)\end{array}$ & $\begin{array}{l}58.0 \pm \\
3.5 \\
(6.7 \pm \\
1.7)\end{array}$ & $\begin{array}{l}56.4 \pm \\
3.5 \\
(5.9 \pm \\
1.7)\end{array}$ & $\begin{array}{l}55.2 \pm \\
3.4 \\
(5.4 \pm \\
1.6)\end{array}$ & $<.0001$ & $\begin{array}{l}a: p= \\
0.0001 \\
b: p< \\
0.0001 \\
c: p< \\
0.0001 \\
d: p= \\
0.0263\end{array}$ & $\begin{array}{l}e: p< \\
0.0001 \\
f: p< \\
0.0001 \\
g: p= \\
0.0188 \\
h: p< \\
0.0001\end{array}$ \\
\hline $\begin{array}{l}\text { SEA } \\
\text { MR }\end{array}$ & $\begin{array}{l}60.3 \pm \\
4.0 \\
(7.7 \pm \\
1.8)\end{array}$ & $\begin{array}{l}59.4 \pm \\
3.9 \\
(7.3 \pm \\
1.8)\end{array}$ & $\begin{array}{l}58.0 \pm \\
3.8 \\
(6.6 \pm \\
1.9)\end{array}$ & $\begin{array}{l}56.4 \pm \\
3.7 \\
(5.9 \pm \\
1.8)\end{array}$ & $\begin{array}{l}55.2 \pm \\
3.7 \\
(5.4 \pm \\
1.8)\end{array}$ & $<.0001$ & $\begin{array}{l}a: p= \\
0.0002 \\
b: p< \\
0.0001 \\
c: p< \\
0.0001 \\
d: p= \\
0.0377\end{array}$ & $\begin{array}{l}\mathrm{e}: \mathrm{p}< \\
0.0001 \\
\mathrm{f}: \mathrm{p}< \\
0.0001 \\
\mathrm{~h}: \mathrm{p}< \\
0.0001\end{array}$ \\
\hline $\begin{array}{l}\text { SEA } \\
\text { CR }\end{array}$ & $\begin{array}{l}59.4 \pm \\
3.7 \\
(7.4 \pm \\
1.7)\end{array}$ & $\begin{array}{l}58.5 \pm \\
3.6 \\
(6.9 \pm \\
1.7)\end{array}$ & $\begin{array}{l}57.1 \pm \\
3.6 \\
(6.2 \pm \\
1.7)\end{array}$ & $\begin{array}{l}55.5 \pm \\
3.5 \\
(5.4 \pm \\
1.7)\end{array}$ & $\begin{array}{l}54.3 \pm \\
3.4 \\
(4.9 \pm \\
1.7)\end{array}$ & $<.0001$ & $\begin{array}{l}a: p< \\
0.0001 \\
b: p< \\
0.0001 \\
c: p< \\
0.0001 \\
e: p< \\
0.0001\end{array}$ & $\begin{array}{l}f: p< \\
0.0001 \\
g: p= \\
0.0126 \\
h: p< \\
0.0001\end{array}$ \\
\hline Total & $\begin{array}{l}60.7 \pm \\
7.8\end{array}$ & $\begin{array}{l}59.8 \pm \\
7.5\end{array}$ & $\begin{array}{l}58.4 \pm \\
7.5\end{array}$ & $\begin{array}{l}56.8 \pm \\
7.3\end{array}$ & $\begin{array}{l}55.6 \pm \\
7.2\end{array}$ & $<.0001$ & $\begin{array}{l}a: p< \\
0.0001\end{array}$ & $\begin{array}{l}f: p< \\
0.0001\end{array}$ \\
\hline
\end{tabular}


$(7.9 \pm$

1.8)
$(7.5 \pm$

1.8)
$(6.8 \pm$

1.9)
$(6.0 \pm$

1.8)
$(5.6 \pm$

1.8) $\begin{array}{ll}\mathrm{b}: \mathrm{p}< & \mathrm{g}: \mathrm{p}< \\ 0.0001 & 0.0001\end{array}$

$c: p<$

0.0001

$\mathrm{h}: \mathrm{p}<$

0.0001

$\mathrm{d}: \mathrm{p}<\quad \mathrm{i}: \mathrm{p}=$

$0.0001 \quad 0.0072$

e : p <

0.0001 $\mathrm{j}: \mathrm{p}=$

0.0043

The values of component size are given as the mean with standard deviation. The values of anteroposterior dimension are shown in parentheses as the mean with standard deviation.

MA: Mechanical axis, CEA: Clinical epicondylar axis, SEA: Surgical epicondylar axis, MR: Medial rotation type of reference guide, $C R$ : Central rotation type of reference guide, P-MA: Perpendicular to MA, $3^{\circ} \mathrm{E}-\mathrm{MA}$ : $3^{\circ}$ extension to $\mathrm{MA}, 5^{\circ} \mathrm{E}-\mathrm{MA}: 5^{\circ}$ extension to $\mathrm{MA}, 3^{\circ} \mathrm{F}-\mathrm{MA}: 3^{\circ}$ flexion to MA, $5^{\circ} \mathrm{F}-\mathrm{MA}: 5^{\circ}$ flexion to $\mathrm{MA}$

The difference among five cutting direction were analyzed with using ANOVA and Steel-Dwass test

a significant difference between $5^{\circ} \mathrm{E}-\mathrm{MA}$ and P-MA $(\mathrm{p}<0.05),{ }^{\mathrm{b}}$ significant difference between $5^{\circ} \mathrm{E}-\mathrm{MA}$ and $3^{\circ} \mathrm{F}-\mathrm{MA}(\mathrm{p}<0.05),{ }^{\mathrm{c}}$ significant difference between $5^{\circ} \mathrm{E}-\mathrm{MA}$ and $5^{\circ} \mathrm{F}-\mathrm{MA}(\mathrm{p}<0.05),{ }^{\mathrm{d}}$ significant difference between $3^{\circ} \mathrm{E}-\mathrm{MA}$ and P-MA $(p<0.05),{ }^{e}$ significant difference between $3^{\circ} \mathrm{E}-\mathrm{MA}$ and $3^{\circ} \mathrm{F}-\mathrm{MA}(p<0.05),{ }^{f}$ significant difference between $3^{\circ} \mathrm{E}-\mathrm{MA}$ and $5^{\circ} \mathrm{F}-\mathrm{MA}(\mathrm{p}<0.05),{ }^{g}$ significant difference between P-MA and $3^{\circ} \mathrm{F}-\mathrm{MA}(\mathrm{p}<0.05),{ }^{\mathrm{h}}$ significant difference between P-MA and $5^{\circ} \mathrm{F}-\mathrm{MA}(\mathrm{p}<0.05),{ }^{i}$ significant difference between $5^{\circ} \mathrm{E}-\mathrm{MA}$ and $3^{\circ} \mathrm{E}-\mathrm{MA}(\mathrm{p}<0.05),{ }^{\mathrm{j}}$ significant difference between $3^{\circ} \mathrm{F}-\mathrm{MA}$ and $5^{\circ} \mathrm{F}-\mathrm{MA}(p<0.05)$

Table 3. Mean anteroposterior dimension and component size with two different rotational alignments 


\begin{tabular}{|c|c|c|c|c|c|c|}
\hline \multirow[t]{2}{*}{$\begin{array}{l}\text { Cutting directions, } \\
\text { rotational type }\end{array}$} & \multicolumn{2}{|c|}{$\begin{array}{l}\text { AP dimension (mm) } \\
\text { (component size) }\end{array}$} & \multirow[t]{2}{*}{ p-value } & \multicolumn{3}{|c|}{ Rate of component size (\%) } \\
\hline & CEA & SEA & & CEA $>S E A$ & CEA $=S E A$ & CEA $<$ SEA \\
\hline \multirow[t]{2}{*}{$5^{\circ} \mathrm{E}-\mathrm{MA}, \mathrm{MR}$} & $62.5 \pm 4.0$ & $60.3 \pm 4.0$ & $<0.0001$ & 88.1 & 11.9 & 0 \\
\hline & $(8.8 \pm 1.7)$ & $(7.7 \pm 1.8)$ & & & & \\
\hline \multirow[t]{2}{*}{$3^{\circ} \mathrm{E}-\mathrm{MA}, \mathrm{MR}$} & $61.7 \pm 3.9$ & $59.4 \pm 3.9$ & $<0.0001$ & 83.2 & 16.8 & 0 \\
\hline & $(8.3 \pm 1.7)$ & $(7.3 \pm 1.8)$ & & & & \\
\hline \multirow[t]{2}{*}{ P-MA, MR } & $60.3 \pm 3.8$ & $58.0 \pm 3.8$ & $<0.0001$ & 88.1 & 11.9 & 0 \\
\hline & $(7.7 \pm 1.7)$ & $(6.6 \pm 1.9)$ & & & & \\
\hline \multirow[t]{2}{*}{$3^{\circ} \mathrm{F}-\mathrm{MA}, \mathrm{MR}$} & $58.6 \pm 3.8$ & $56.4 \pm 3.7$ & $<0.0001$ & 87.1 & 12.9 & 0 \\
\hline & $(6.9 \pm 1.7)$ & $(5.9 \pm 1.8)$ & & & & \\
\hline \multirow[t]{2}{*}{$5^{\circ} \mathrm{F}-\mathrm{MA}, \mathrm{MR}$} & $57.5 \pm 3.7$ & $55.2 \pm 3.7$ & $<0.0001$ & 93.1 & 6.9 & 0 \\
\hline & $(6.5 \pm 1.8)$ & $(5.4 \pm 1.8)$ & & & & \\
\hline \multirow[t]{2}{*}{$5^{\circ} \mathrm{E}-\mathrm{MA}, \mathrm{CR}$} & $60.3 \pm 3.7$ & $59.4 \pm 3.7$ & 0.0814 & 39.6 & 60.4 & 0 \\
\hline & $(7.7 \pm 1.7)$ & $(7.4 \pm 1.7)$ & & & & \\
\hline \multirow[t]{2}{*}{$3^{\circ} \mathrm{E}-\mathrm{MA}, \mathrm{CR}$} & $59.4 \pm 3.6$ & $58.5 \pm 3.6$ & 0.0653 & 43.6 & 56.4 & 0 \\
\hline & $(7.3 \pm 1.6)$ & $(6.9 \pm 1.7)$ & & & & \\
\hline \multirow[t]{2}{*}{ P-MA, CR } & $58.0 \pm 3.5$ & $57.1 \pm 3.6$ & 0.0656 & 47.5 & 52.5 & 0 \\
\hline & $(6.7 \pm 1.7)$ & $(6.2 \pm 1.7)$ & & & & \\
\hline \multirow[t]{2}{*}{$3^{\circ} \mathrm{F}-\mathrm{MA}, \mathrm{CR}$} & $56.4 \pm 3.5$ & $55.5 \pm 3.5$ & 0.0562 & 50.5 & 49.5 & 0 \\
\hline & $(5.9 \pm 1.7)$ & $(5.4 \pm 1.7)$ & & & & \\
\hline \multirow[t]{2}{*}{$5^{\circ} \mathrm{F}-\mathrm{MA}, \mathrm{CR}$} & $55.2 \pm 3.4$ & $54.3 \pm 3.4$ & 0.0524 & 46.5 & 53.5 & 0 \\
\hline & $(5.4 \pm 1.6)$ & $(4.9 \pm 1.7)$ & & & & \\
\hline \multirow[t]{2}{*}{ Total } & $59.1 \pm 4.3$ & $57.5 \pm 4.1$ & $<0.0001$ & 70.5 & 31.2 & 0 \\
\hline & $(6.5 \pm 1.9)$ & $(5.7 \pm 1.9)$ & & & & \\
\hline
\end{tabular}

The values are given as the mean with standard deviation.

AP: anteroposterior, MA: Mechanical axis, CEA: Clinical epicondylar axis, SEA: Surgical epicondylar axis, MR: Medial rotation type of reference guide, CR: Central rotation type of reference guide, P-MA:

Perpendicular to MA, $3^{\circ} \mathrm{E}-\mathrm{MA}: 3^{\circ}$ extension to MA, $5^{\circ} \mathrm{E}-\mathrm{MA}: 5^{\circ}$ extension to MA, $3^{\circ} \mathrm{F}-\mathrm{MA}: 3^{\circ}$ flexion to $\mathrm{MA}$, $5^{\circ} \mathrm{F}-\mathrm{MA}: 5^{\circ}$ flexion to MA, 
p-value means difference between CEA and SEA

Table 4. Mean anteroposterior dimension and component size with two different anterior reference guides

\begin{tabular}{|c|c|c|c|c|c|c|}
\hline \multirow[t]{2}{*}{$\begin{array}{l}\text { Cutting directions, } \\
\text { rotational alignment }\end{array}$} & \multicolumn{2}{|c|}{$\begin{array}{l}\text { AP dimension }(\mathrm{mm}) \\
\text { (component size) }\end{array}$} & \multirow[t]{2}{*}{ p-value } & \multicolumn{3}{|c|}{ Rate of component size (\%) } \\
\hline & MR & CR & & $\mathrm{MR}>\mathrm{CR}$ & $M R=C R$ & $M R<C R$ \\
\hline \multirow[t]{2}{*}{$5^{\circ} \mathrm{E}-\mathrm{MA}, \mathrm{CEA}$} & $62.5 \pm 4.0$ & $60.3 \pm 3.7$ & $<0.0001$ & 87.1 & 12.9 & 0 \\
\hline & $(8.8 \pm 1.7)$ & $(7.7 \pm 1.7)$ & & & & \\
\hline \multirow[t]{2}{*}{$3^{\circ} \mathrm{E}-\mathrm{MA}, \mathrm{CEA}$} & $61.7 \pm 3.9$ & $59.4 \pm 3.6$ & $<0.0001$ & 87.1 & 12.9 & 0 \\
\hline & $(8.3 \pm 1.7)$ & $(7.3 \pm 1.6)$ & & & & \\
\hline \multirow[t]{2}{*}{ P-MA, CEA } & $60.3 \pm 3.8$ & $58.0 \pm 3.5$ & $<0.0001$ & 85.1 & 14.9 & 0 \\
\hline & $(7.7 \pm 1.7)$ & $(6.7 \pm 1.7)$ & & & & \\
\hline \multirow[t]{2}{*}{$3^{\circ} \mathrm{F}-\mathrm{MA}, \mathrm{CEA}$} & $58.6 \pm 3.8$ & $56.4 \pm 3.5$ & $<0.0001$ & 82.2 & 17.8 & 0 \\
\hline & $(6.9 \pm 1.7)$ & $(5.9 \pm 1.7)$ & & & & \\
\hline \multirow[t]{2}{*}{$5^{\circ} \mathrm{F}-\mathrm{MA}, \mathrm{CEA}$} & $57.5 \pm 3.7$ & $55.2 \pm 3.4$ & $<0.0001$ & 91.1 & 8.9 & 0 \\
\hline & $(6.5 \pm 1.8)$ & $(5.4 \pm 1.6)$ & & & & \\
\hline \multirow[t]{2}{*}{$5^{\circ} \mathrm{E}-\mathrm{MA}, \mathrm{SEA}$} & $60.3 \pm 4.0$ & $59.4 \pm 3.7$ & 0.094 & 38.6 & 58.4 & 3.0 \\
\hline & $(7.7 \pm 1.8)$ & $(7.4 \pm 1.7)$ & & & & \\
\hline \multirow[t]{2}{*}{$3^{\circ} \mathrm{E}-\mathrm{MA}, \mathrm{SEA}$} & $59.4 \pm 3.9$ & $58.5 \pm 3.6$ & 0.0751 & 43.6 & 53.4 & 3.0 \\
\hline & $(7.3 \pm 1.8)$ & $(6.9 \pm 1.7)$ & & & & \\
\hline \multirow[t]{2}{*}{ P-MA, SEA } & $58.0 \pm 3.8$ & $57.1 \pm 3.6$ & 0.0748 & 39.6 & 59.4 & 1.0 \\
\hline & $(6.6 \pm 1.9)$ & $(6.2 \pm 1.7)$ & & & & \\
\hline \multirow[t]{2}{*}{$3^{\circ} \mathrm{F}-\mathrm{MA}, \mathrm{SEA}$} & $56.4 \pm 3.7$ & $55.5 \pm 3.5$ & 0.0682 & 47.5 & 51.5 & 1.0 \\
\hline & $(5.9 \pm 1.8)$ & $(5.4 \pm 1.7)$ & & & & \\
\hline \multirow[t]{2}{*}{$5^{\circ} \mathrm{F}-\mathrm{MA}, \mathrm{SEA}$} & $55.2 \pm 3.7$ & $54.3 \pm 3.4$ & 0.0616 & 41.6 & 56.4 & 2.0 \\
\hline & $(5.4 \pm 1.8)$ & $(4.9 \pm 1.7)$ & & & & \\
\hline \multirow[t]{2}{*}{ Total } & $59.1 \pm 4.4$ & $57.5 \pm 4.0$ & $<0.0001$ & 64.5 & 34.8 & 0.7 \\
\hline & $(6.5 \pm 1.9)$ & $(5.7 \pm 1.8)$ & & & & \\
\hline
\end{tabular}


The values are given as the mean with standard deviation.

AP: anteroposterior, MA: Mechanical axis, CEA: Clinical epicondylar axis, SEA: Surgical epicondylar axis, MR: Medial rotation type of reference guide, CR: Central rotation type of reference guide, P-MA:

Perpendicular to MA, $3^{\circ} \mathrm{E}-\mathrm{MA}: 3^{\circ}$ extension to MA, $5^{\circ} \mathrm{E}-\mathrm{MA}: 5^{\circ}$ extension to MA, $3^{\circ} \mathrm{F}-\mathrm{MA}: 3^{\circ}$ flexion to MA, $5^{\circ} \mathrm{F}-\mathrm{MA}: 5^{\circ}$ flexion to MA

p-value means difference between MR and CR

\section{Figures}

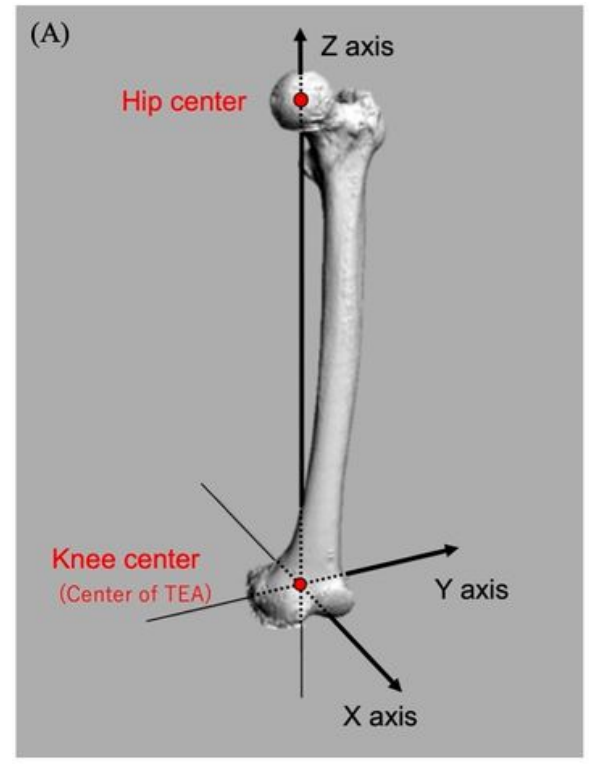

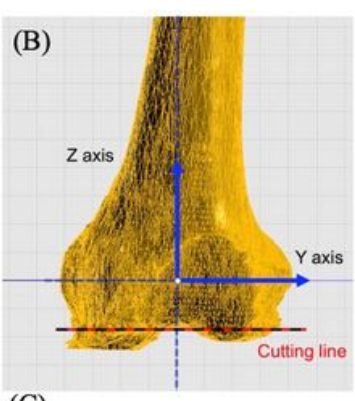

(C)

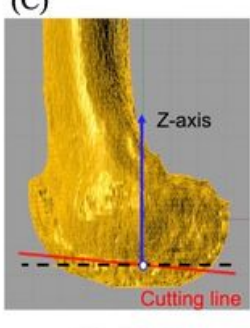

$5^{\circ}$ E-MA

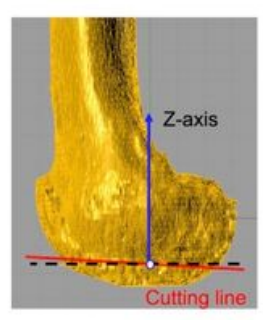

$3^{\circ}$ E-MA

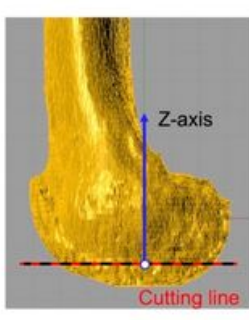

P-MA

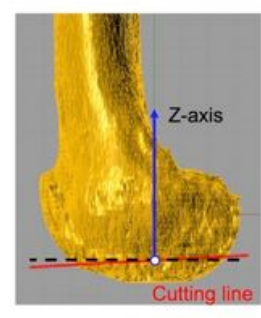

$3^{\circ}$ F-MA

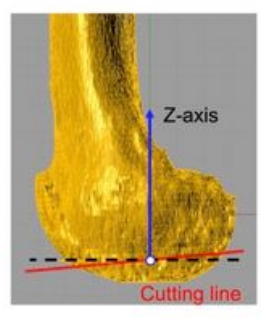

$5^{\circ}$ F-MA

\section{Figure 1}

(A) Three-dimensional coordinates for virtual surgery (B) Bone cutting for distal femur (Coronal plane) (C) Bone cutting for distal femur (Sagittal plane) TEA: Transepicondylar axis Z-axis (proximal-distal): The extension of femoral mechanical axis Y-axis (medial-lateral): The extension of functional TEA which was projected TEA onto the plane perpendicular to femoral mechanical axis at the knee center X-axis (anteriorposterior): The line normal to the coronal plane (YZ-plane) at the knee center Red line: Cutting line $5^{\circ} \mathrm{E}-$ MA: $5^{\circ}$ extension relative to femoral MA $3^{\circ} \mathrm{E}-\mathrm{MA}: 3^{\circ}$ extension relative to femoral MA P-MA: Perpendicular to femoral MA $3^{\circ} \mathrm{F}-\mathrm{MA}: 3^{\circ}$ flexion relative to femoral MA $5^{\circ} \mathrm{F}-\mathrm{MA}: 5^{\circ}$ flexion relative to femoral MA 
(A)
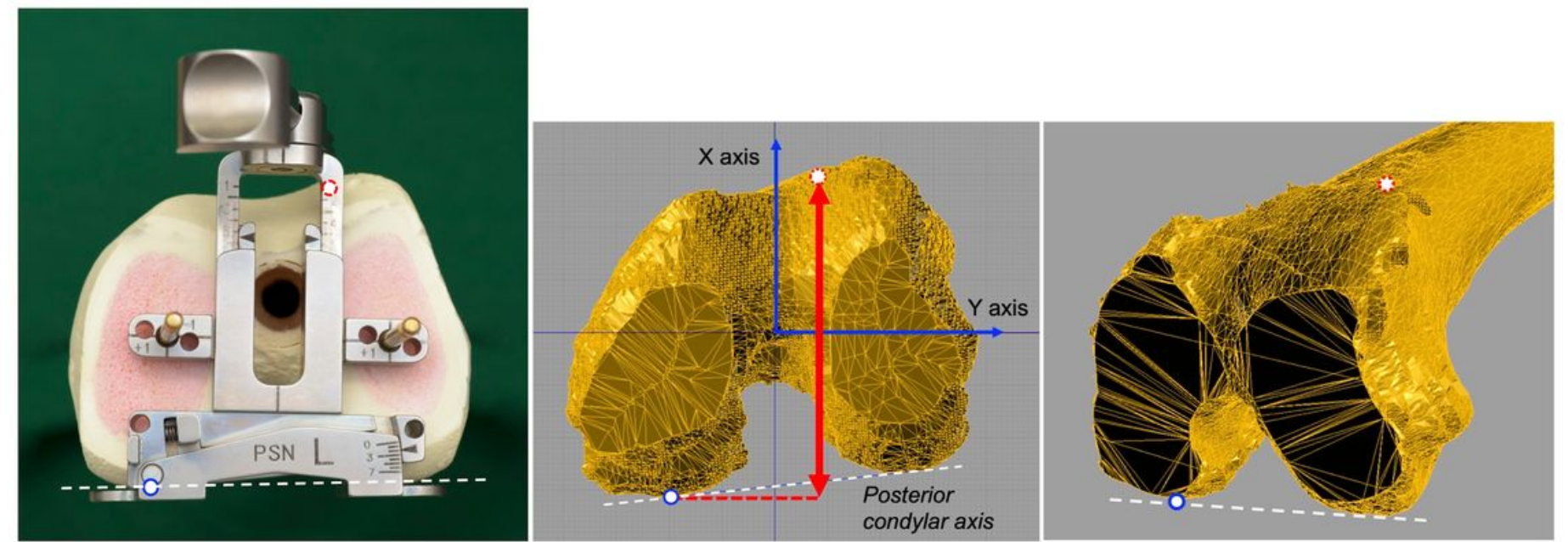

(B)
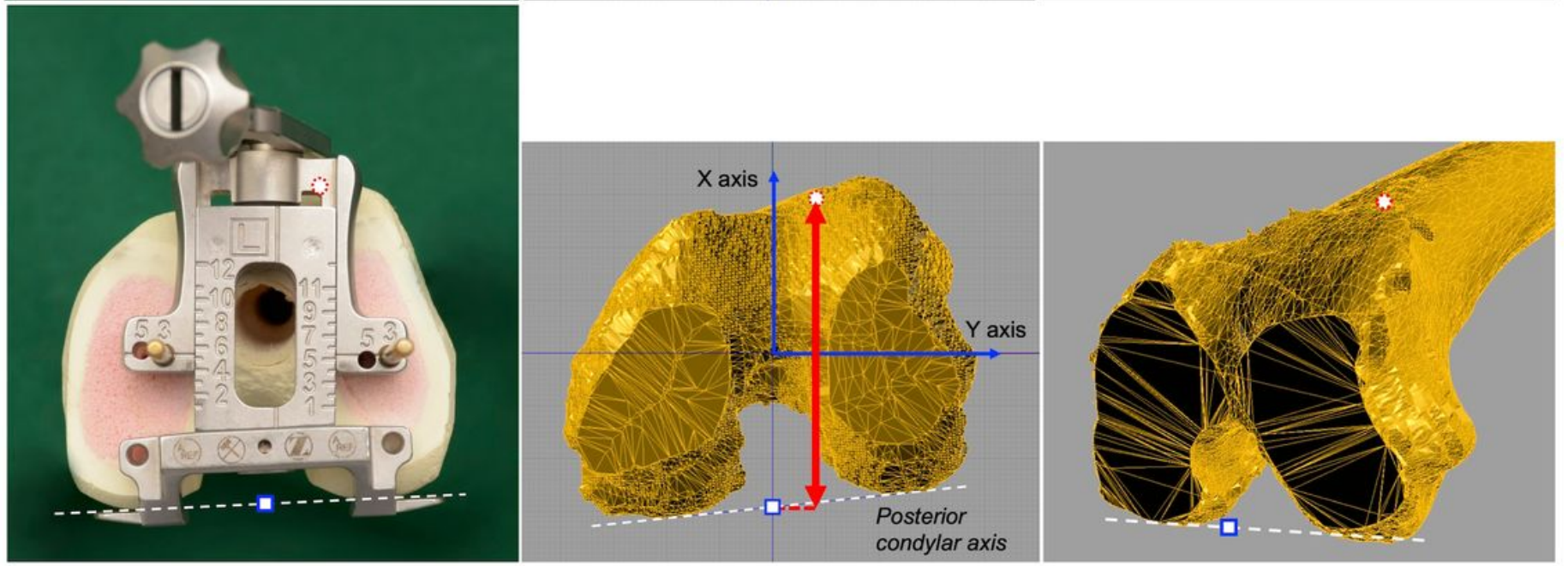

\section{Figure 2}

Medial and central rotation type of reference guide (A) Medial rotation type (B) Central rotation type Red dotted circle: Attachment of anterior boom White dotted line: Posterior condylar axis Red bidirectional arrows: Anteroposterior dimension in the XY-plane Blue lined circle and blue lined square: Rotation center
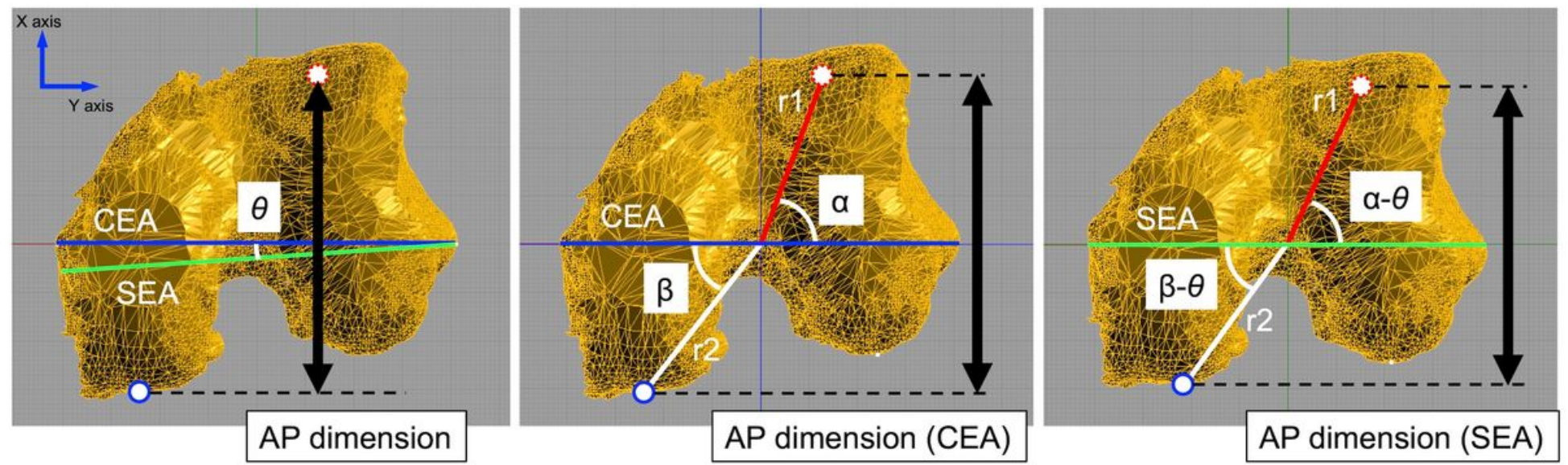

Figure 3 
Anteroposterior (AP) dimension using CEA and using SEA on the XY-plane CEA: Clinical epicondylar axis SEA: Surgical epicondylar axis Blue lined circle: Rotation center of reference guide Red dotted circle: Attachment of anterior boom AP dimension (CEA) $=r 1 \times \sin \alpha+r 2 \times \sin \beta$ AP dimension (SEA) $=r 1 \times \sin (a-\theta)$ $+r 2 \times \sin (\beta-\theta) r 1$ : Distance between knee center and attachment of anterior boom r2: Distance between knee center and rotation center of reference guide $\theta$ : Angle between CEA and SEA a: Angle between CEA and line connecting knee center and attachment of anterior boom $\beta$ : Angle between CEA and line connecting knee center and rotation center of reference guide $\alpha-\theta$ : Angle between SEA and line connecting knee center and attachment of anterior boom $\beta-\theta$ : Angle between SEA and line connecting knee center and rotation center of reference guide

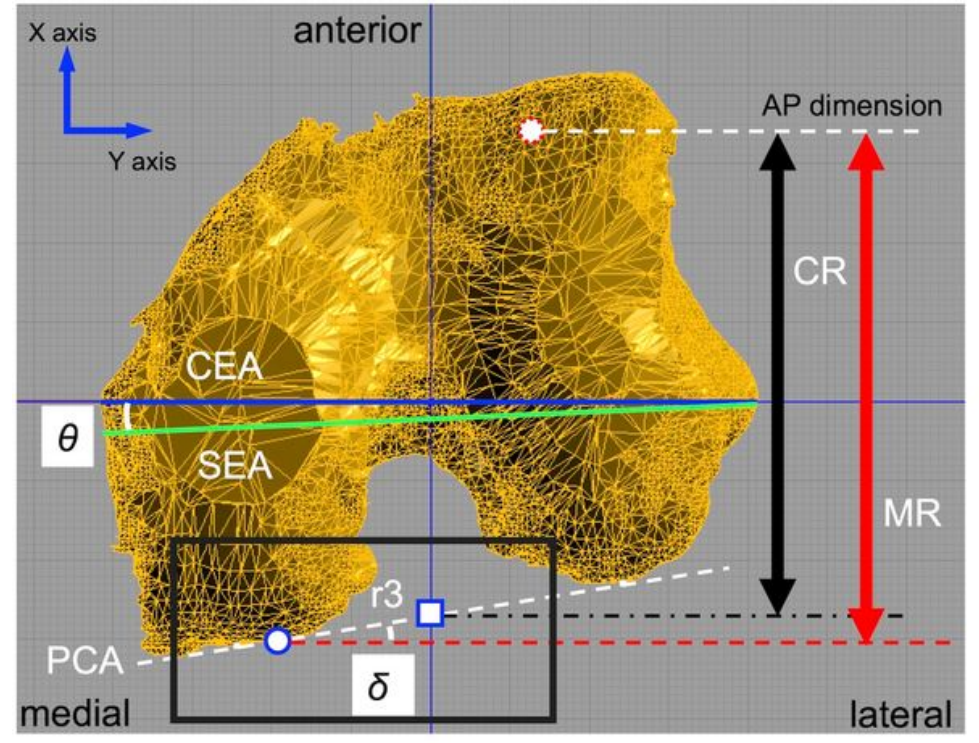

Rotational alignment: CEA

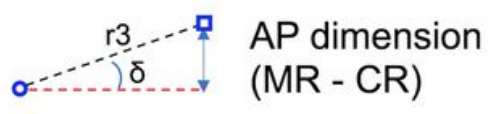

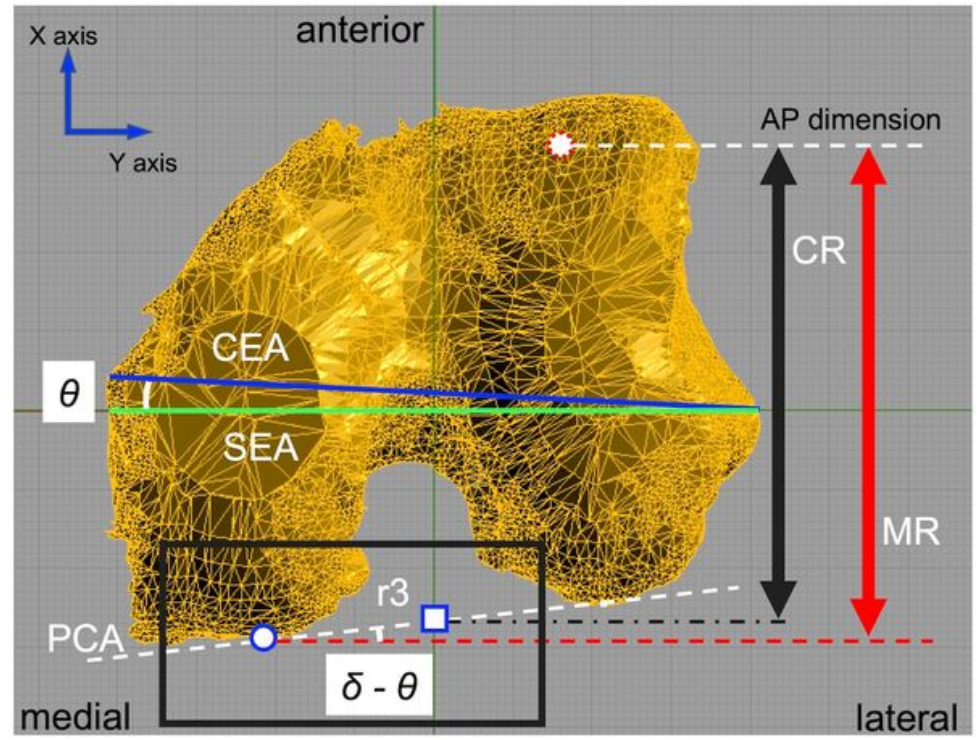

Rotational alignment: SEA

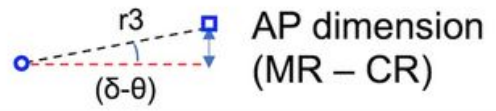

\section{Figure 4}

Difference in anteroposterior (AP) dimension using MR or CR in the XY-plane MR: Medial rotation type of reference guide CR: Central rotation type of reference guide (Left) Target rotational alignment: CEA (Right) Target rotational alignment: SEA CEA: Clinical epicondylar axis SEA: Surgical epicondylar axis PCA: Posterior condylar axis Blue lined circle: Rotation center of MR Blue lined square: Rotation center of CR Red dotted circle: Attachment of anterior boom Difference of AP dimension between using MR and CR $(C E A)=r 3 \times \sin \delta$ Difference of AP dimension between using MR and CR (SEA) $=r 3 \times \sin (\delta-\theta) r 3$ : Distance between rotation center of MR and rotation center of $C R \theta$ : Angle between CEA and SEA $\delta$ : Angle between CEA and PCA 